\title{
An Empirical Study on E-commerce's effects on Economic Growth
}

\author{
Sixun Liu \\ Department of Economics, \\ Xiamen University, \\ Xiamen, China \\ e-mail: liusixunjiayou@163.com
}

\begin{abstract}
With the rapid development of computer network technology and information and communication technology, e-commerce has become an economic hot spot and trend. Based on the GDP accounting by expenditure method, this paper analyses and expounds the impact mechanism of e-commerce development to the national economic growth. It uses econometric model to get empirical research between e-commerce development and economic growth using the latest data of Chinese e-commerce development to reach the conclusion that e-commerce can promote economic growth. At last, the paper proposes appropriate e-commerce development approaches to make e-commerce have a greater role in economic growth.
\end{abstract}

Keywords-e-commerce; economic growth; expenditure method; empirical analysis

\section{INTRODUCTION}

Accompanied by the continuous development of modern information technology and global economic integration, e-commerce came into being. E-commerce refers to the sum of commercial activities and non-profit business or service activities with the application of modern computer, network technology and modern information communication technology and it is a new form of trade emerged with the application of electronic information technology in trade field. Compared with the previous traditional business, e-commerce has several distinct advantages such as fewer links, faster speed and smaller pressure of inventories for enterprises.

During more than ten years' development of e-commerce in China, the scale of e-commerce industry has gradually expanded, with more and more people being engaged in this industry. A good environment including favorable infrastructure, policy and market makes e-commerce to flourish, especially since 2006, Chinese e-commerce has enjoyed a rapid development and increasing expanding market scale, entering into a period of rapid growth , with an inspiring developing trend. The financial crisis in 2008 swept the world and each country's economy is affected in different degree, while the development of e-commerce has shown us its infinite vitality. The total volume of China's e-commerce transactions in 2008 has exceeded 3 trillion Yuan, with an increase of more than forty percent compared to the same period. The year of 2009 is an e-commerce year, during which, the development of domestic B2B e-commerce has played a tremendous role in helping small and medium enterprises tide over the difficulty, stimulating domestic demand and creating jobs. It is exactly with its unique business model and inherent potential that e-commerce has attracted widespread concern and developed a new area of study for scholars.

As we all know, there is a close relationship between e-commerce and national economy. A series of microscopic behavior with positive effect exerted on enterprises by e-commerce will definitely lead to macro-economic development and accelerate the development of national economy. There is no doubt that e-commerce can promote the transformation of economic growth pattern. It not only inject new vitality into more high-tech companies, drive the structure optimization and upgrade the traditional industries, but also become the growth point of China's modern logistics industry and economic development. Hence, with the increasing economic globalization and developing information technology nowadays, it is necessary for further research into the impact mechanism and concrete impact on China's economic growth exerted by e-commerce, which will help our country to exert subsequent advantages and seize the favorable opportunities of the development of e-commerce in order to realize the economic surpassing strategy for this century.

\section{THE MECHANISM OF E-COMMERCE'S EFFECTS ON ECONOMIC GROWTH}

The gross domestic product (GDP) is considered to be a relatively good indicator to reflect the economic development level. The analysis of the mechanism of e-commerce's effects on economic growth is based on the expenditure method of GDP accounting. According to the expenditure method, GDP is composed of consumption, investment, government purchase and net export, which is $G D P=C+I+G+(X-M)$ by formula. How e-commerce stimulates economic growth through the consumption, investment, government purchase and net export is discussed following and the mechanism provides a theoretical basis for the following empirical analysis. Firstly, the development of e-commerce has led to the development of some emerging industries such as logistics, and created more jobs in industries such as computers and the internet, thus stimulates the consumption. Since e-commerce has provided people with a wide variety of products and met people's material and cultural needs to a greater extent, more and more consumers have been keen in online shopping, increasing the consumption spending. E-commerce, with its efficiency 
and convenience and the characteristics of breaking through the limit of time and space, it has largely attracted businesses and consumers, both of which can work together to promote economic development. Besides, if consumers are optimistic about the prospects of e-commerce, they will spend more on things such as computers, which will also lead to the increase of consumption.

Secondly, in terms of investment, to compete for the customers, all e-commerce companies must guarantee to provide items within the scope of the time and place specified by the customers to meet their demands, which will require a large amount of money in related areas such as quantitative stock, transport infrastructure, leading to the increase in fixed capital investment. The prosperity of e-commerce has also brought the prosperity of other industries, such as the advertising industry. The development of e-commerce has promoted the development of network advertisement and stimulated the potential of advertising investment demand. From a practical point of view, e-commerce can expand the sources of funding and support the construction of economic system. Facing the global financial crisis in 2008, e-commerce was the important choice for company in China to tide over the difficulty.

Thirdly, in order to meet the transportation demands required by the rapid development of e-commerce, the increasing demands for related roads and transportation means, which will lead to an corresponding increase of government procurement in this area . Similarly, in response to the growth of auxiliary services demands, infrastructures such as power generation and communication network must be upgraded, which will also increase government procurement expenditures. In addition, due to the strict requirement of e-commerce on network data security, corporate business credit and personal credit, government will increase related procurement expenditures to ensure the normal operation of e-commerce.

Finally, since e-commerce has achieved a smooth flow of information dissemination, it is beneficial to help improve the international reputation of its enterprise products and services, which undoubtedly has played an important role in expanding exports. Besides, the applications of e-commerce enable us to participate in the international market competition more effectively and gain advantages and initiative to obtain greater benefits in the process of economic globalization and promote rapid and healthy development of economy.

\section{EMPIRICAL ANALYSIS OF E-COMMERCE'S EFFECTS ON ECONOMIC GROWTH}

\section{A. Selection of Variables and Data}

Based on the analysis above, e-commerce can promote economic growth through four components of GDP by expenditure approach accounting. Therefore, this paper chooses several related indicators representing consumption, investment, government purchases and net exports respectively to reflect the development of e-commerce, and chooses GDP to represent the level of economic development to carry out an empirical analysis of the relationship between the two parts.

To be specific, the development of e-commerce has stimulated consumption via the increase in the number of internet users and the number of online shopping users, while positive changes in the size of the scale of online advertising reflect an expected positive change in investment, the increase in the number of $\mathrm{CN}$ domain name and website reflects the increase of government purchase, and the increase of the number of international outlet bandwidth can increase net exports. Therefore, we selected the GDP as the dependent variable, the number of $\mathrm{CN}$ domain name $(\mathrm{CN})$, the international outlet bandwidth (DK), the number of Internet users (SWYH), the number of online shopping users (WGRS), the scale of online advertising (WLGG) and the number of websites (WWW) as independent variables to set the model as follows.

$G D P=C+\beta_{1} C N+\beta_{2} D K+\beta_{3} W Y H+\beta_{4} W G R S+\beta_{5} W L G G+\beta_{6} W W W+\mu$

In order to eliminate the smoothness of the data, these variables were natural logarithm. This paper uses the time series data to estimate the regression model, and adopt the data from the China Statistical Yearbook 1997-2011, "China Internet Development Status Analysis Report" (1-29th) issued by the China Internet Network Information Center, and "Investigation Report on Chinese E-commerce from 1997 to2009 " provided by B2B Research Center in China as a sample to carry out correlation and regression analysis.

\section{B. Data Stationary Test}

When using regression methods to study the relationship between time series, one must first examine whether the original sequence is stationary. If the original sequence is non-stationary, then though the regression test shows that there is a significant relationship between the sequences, this return is in fact " spurious regression" . Therefore, it is necessary to first test the stationarity of all the variables before the co-integration test. This paper adopted the ADF unit root test; the following table shows the results of unit root test of original sequence of each variable and the first order differential sequence:

TABLE I. TIME SERIES OF ADF UNIT ROOT TEST

\begin{tabular}{|l|l|l|l|l|}
\hline Variable & $\begin{array}{c}\text { Method } \\
(\mathbf{C}, \mathbf{T , K})\end{array}$ & $\begin{array}{c}\text { ADF } \\
\text { Statistic }\end{array}$ & $\begin{array}{c}\mathbf{5 \%} \text { Critical } \\
\text { value }\end{array}$ & Conclusion \\
\hline GDP & $(\mathrm{c}, 0,3)$ & -2.573425 & -3.175352 & non-stationary \\
\hline $\mathrm{CN}$ & $(\mathrm{c}, 0,0)$ & -2.411520 & -3.098896 & non-stationary \\
\hline DK & $(\mathrm{c}, \mathrm{t}, 2)$ & -3.021037 & -3.875302 & non-stationary \\
\hline SWYH & $(0,0,1)$ & -0.247916 & -1.970978 & non-stationary \\
\hline WGRS & $(0,0,2)$ & -0.344027 & -1.602922 & non-stationary \\
\hline WLGG & $(\mathrm{c}, 0,2)$ & -2.233257 & -3.144920 & non-stationary \\
\hline WWW & $(\mathrm{c}, \mathrm{t}, 0)$ & -2.013571 & -3.791172 & non-stationary \\
\hline$\triangle$ GDP & $(\mathrm{c}, 0,3)$ & -3.942752 & -3.212696 & stationary \\
\hline$\triangle \mathrm{CN}$ & $(0,0,0)$ & -2.338408 & -1.970978 & stationary \\
\hline$\triangle \mathrm{DK}$ & $(\mathrm{c}, \mathrm{t}, 3)$ & -8.073435 & -4.008157 & stationary \\
\hline$\triangle \mathrm{SWYH}$ & $(0,0,0)$ & -2.249905 & -1.970978 & stationary \\
\hline$\triangle \mathrm{WGRS}$ & $(\mathrm{c}, 0,3)$ & -4.663327 & -3.212696 & stationary \\
\hline$\triangle \mathrm{WLGG}$ & $(\mathrm{c}, 0,2)$ & -6.269093 & -3.175352 & stationary \\
\hline$\triangle \mathrm{WWW}$ & $(0,0,0)$ & -2.426158 & -1.970978 & stationary \\
\hline
\end{tabular}


It can be seen from the table above that, under the significant level of 5\%, the absolute value of all variables of the original sequence of the ADF test values are all below the absolute value of the threshold of $5 \%$, which means that the original sequence of each variable exists unit root, that is , they are non-stationary. Their first-order differential absolute values of the ADF test values are all surpass the absolute value of the $1 \%$ threshold, indicating that the first difference sequence of each variable does not have unit root and is stationary. Therefore, each variable is first-order stationary, Satisfying the premise of the co-integration test, which makes it possible to further establish the long-term co-integration equation on GDP and each explanatory variable.

\section{Co-integration Test}

The objects of the co-integration test can be divided into two kinds: one test is based on the regression coefficient, which is the Johansen test; another is based on regression residuals, such as the ADF test. Taken the actual situation and scope of application of each test method into consideration, this paper takes the second co-integration test methods.

First of all, under the premise that all the variables are first order stationary, the regression equation can be estimated as follows:

$$
\begin{aligned}
& G D P=14.2541327109+0.126125363057 \mathrm{CN}+ \\
& 0.225294871201 \mathrm{DK}+0.283105731849 \mathrm{SWYH}+ \\
& 0.196238624245 \mathrm{WGRS}+0.580651974925 \mathrm{WLGG} \\
& +0.170317687317 \mathrm{WWW} \\
& t=(23.19447) \quad(2.486621) \quad(2.721281) \quad(2.880147) \\
& \begin{array}{l}
(2.398653)(5.931531)(2.912025) \\
\text { R-squared }=0.985995, \mathrm{~F}=165.2687, \mathrm{DW}=2.087268
\end{array}
\end{aligned}
$$

It can be observed by looking up the table that under the given significant level of $5 \%$, coefficients of t-statistics of all Explanatory variables have passed the test, indicating that all the estimated values of coefficients are significant. From the perspective of the whole significance of the model, the value of F-statistics is so high that it shows the model overall is significant. Besides, the value of R-squared is up to 0.985995 , indicating the model has high fitting degree. Since the data is time series data, it can be assumed that the heteroscedasticity is non-existent, and that the DW value being 2.087268 shows the serial correlation does not exist.

Secondly, through unit root tests on the residuals of the regression equation, the estimated residual from the estimated results of the regression equation can be obtained as follows:

$$
\mu=G D P-14.2541327109-0.126125363057 C N-
$$
$0.225294871201 \quad D K-0.283105731849$ SWYH 0.196238624245 WGRS -0.580651974925 WLGG -0.170317687317 WWW

The ADF test value of $\mu$ is -3.619330 , and it is higher than the critical value under the significant level of $5 \%$, which is -3.098896 , from which it can be seen that the residual series is stationary, which also verify the co-integration relationship of the empirical model is correct, reflecting the long-run equilibrium relationship between GDP and each factor do exist.

\section{Analysis on Empirical Results}

Based on the analysis above, the regression co-integration equation has a good property and high fitting degree. The value of t-statistics all passing the test under the significant level of 5\% reflects the long-term equilibrium relationship between all variables. In the long run, GDP and other variables are positively correlated as expected, showing that the increase of the number of $\mathrm{CN}$ domain name, international bandwidth, the number of internet users, online shopping number, the scale of online advertising, as well as the number of websites has all played positive roles of growth of GDP, and these variables represent the level of development of e-commerce in consumption, investment, government purchase and net export respectively, so that the conclusion can be drawn that e-commerce is indeed a promoter on the domestic economy. Among these explanatory variables, the coefficient of the scale of online advertising is the highest, indicating that in recent years, the development of e-commerce has accelerated rapid expansion of online advertising investment. The network, with its tremendous influence, has provided a broader platform for the development of the advertising industry, accelerating driven economic growth.

\section{POLICIES AND PROPOSALS}

In order to make e-commerce have a greater role in economic growth, national government, enterprises and consumers need to pay more attention to e-commerce, to increase investment in infrastructure, pushing more internet users to develop online shopping habits so as to improve the overall development level of the e-commerce, thus promoting the effective national economic growth. In this regard, the following four proposals should be taken into consideration:

First, improve the infrastructure of e-commerce systems, and increase government expenditures.

Government should actively support the construction of e-commerce infrastructure, increase government expenditures in the information technology infrastructure and conduct reasonable guide on the funds investment. Meanwhile, it is necessary to accelerate the construction of high-speed information transmission backbone network and broadband Internet, increase Internet speed and reduce Internet access costs. Government should further strengthen the introduction and development of electronic information technology hardware and software and shorten the gap from those countries developed in internet. For those e-commerce development projects which are important but are difficult in investment, government can take a direct investment or government-oriented measure to support the construction of enterprise e-business.

Secondly, promote and improve the electronic settlement system, and promote consumption increase.

In the $\mathrm{B} 2 \mathrm{C}$ area, barriers to online transactions are mainly displayed in the means of payment. Currently, there is not a uniform communication platform applied by each 
State-owned banks, credit card of each bank can not be universal and it is difficult to achieve online payment with credit card. Therefore, it is strongly suggested to establish uniform standards as soon as possible, encourage the commercial banks, CUP, third-party payment services institutions to establish a good working relationship with commercial enterprises and e-commerce businesses and to expand the scope of application of the credit card and other electronic means of payment in order to promote the development of online transactions.

Thirdly, establish online security certification system and promote business investment.

Network security is the issue that enterprises mostly worried about when using e-commerce, so that how to protect the security of e-commerce business activities will always be the core area of e-commerce study. Therefore, the establishment of the mechanism and system of CA is necessary. CA can protect equal status of security of the parties in the transaction on the internet. Besides, CA should be served by the authority authorized by the State to promote e-commerce is operated in the safe, orderly environment.

Last,but not the last, promote the building of logistics system and increase business investment.

All kinds of logistics enterprises should actively improve the level of information, optimize the logistics processes and improve logistics and distribution system to improve the delivery efficiency and reduce logistics costs, and providing good support service for e-commerce. It is also suggested to promote third-party logistics system and improve the specialization of logistics enterprises. Logistics enterprises should actively introduce and utilize foreign advanced logistics technology and equipment to integrate inter-enterprise resources and strengthen cooperation with foreign logistics enterprises. A modern logistics system needs to be gradually established to promote the development of e-commerce.

\section{REFERENCES}

[1] Minghong Zhang, Zhiyuan Zhang and Linlin Zhu, "The Analysis of Online Insurance Investment Strategy Based on Duopoly Game Model", Communications in Computer and Information Science, $\mathrm{v}$ 233 CCIS, n PART 3, 2011, Computing and Intelligent Systems International Conference, ICCIC 2011, Proceedings, pp. 135-142.

[2] Shan $\mathrm{Lu}$ and Ping $\mathrm{Hu}$, "The Impact and Inspiration of E-commerce on China's Economy”.Economy Forum, September,2007.

[3] Yuzhen Fan and Debao Zhuo, "Empirical Research on E-commerce Development and Economic Growth", Industry Technology Economy, August,2010,pp40-44.

[4] Chunmei Ma, "The Impact of E-commerce on Economy and the Strategy of China's Development", Economy Forum, December,2005.

[5] http://www.cnnic.net.cn

[6] http://www.iresearch.cn/ 